beginning before immunization in the first 30 days of life; 5) 8 cases with a history of first seizures recorded at a subsequent visit; and 6) 2 cases of infantile spasms and 5 acute encephalopathies with onset recorded 30 days or more after DTP immunization.

Of 231 post-immunization first seizures selected for study without other predisposing cause in children 30 days of age or older, 55 had afebrile seizures, and 176 had febrile seizures. The incidence of recorded febrile seizures in the immediate post-immunization period was 3.7 times that in the period 30 days or more after immunization. One child suffered a prolonged status epilepticus on the evening of her third DTP shot, and neurologic sequelae included focal epilepsy at 6-yr follow-up. Six cases of first seizures occurred within 30 days of immunization, and the expected incidence without immunization in this time interval was calculated at 5.07. The authors conclude that serious neurologic sequelae of DTP immunization are extremely infrequent in otherwise healthy children. (Walker AM et al. Neurologic events following diphtheria-tetanus-pertussis immunization. Pediatrics March 1988; $81: 345-9)$.

COMERT. The omission of several groups of children from this retrospective epidemiological study detracts from the significance of the conclusions and estimates of incidence of DTP-related febrile and non-febrile seizures. The role of DTP as a precipitating cause in children with a predisposition to seizures and as a possible cause of infantile spasms is neglected. It is unfortunate that the study did not address the known risks of DTP in children with prior neurologic disease or predisposition to seizures including positive family history (see Ped Neur Briefs Nov $1987 ; \underline{1}: 40)$.

\title{
INFANTILE SPASMS
}

Four infants with partial seizures evolving to infantile spasms were investigated using simultaneous EEG-video-telemetry recording in the Dept of Pediatrics, Nagoya University, Nagoya, and Division of Pediatric Neurology, Central Hospital, Aichi Prefectural Colony, Kasugai, Japan. Partial seizures were characterized by cessation of activity, staring, flushing, automatisms, increased tone and laughter. (Yamamoto $\mathrm{N}$, Watanabe $\mathrm{K}$ et al. Partial seizures evolving to infantile spasms. Epilepsia Jan/Feb $1988 ; 29: 34-40$ ).

COMmEN. A cry or scream is the most common ictal element in infantile spasms, and laughter and a frightened or confused expression, manifestations of partial seizures, are frequently described (Jeavons PM, Bower BD. Clinics in Developmental Medicine No 15, 1964, London, Spastics Society and Heinemann). The above report appears to be the first in which infantile spasms were preceded by partial seizures confirmed by EEG-VT. However, one of the above authors, in a previous study of the evolution of EEG abnormalities accompanying infantile spasms, reported hypsarrhythmia preceded by focal sharp wave patterns, compatible with partial seizures (Watanabe $\mathrm{K}$ et al. Dev Med Child Neurol 1973;15:584).

\section{REFLEX EPILEPSY}

\section{HOT WATER EPILEPSY (HWE)}

Seizures precipitated by very hot water-head baths $\left(40-50^{\circ} \mathrm{C}\right)$, a regional religious custom, or showers were seen in 279 patients between 1980-83 in Bangalore, Southern India, and are reported from the Depts of Neurology and 